\title{
PENGEMBANGAN MODEL BLENDED LEARNING BERBASIS LEARNING MANAGEMENT SYSTEM DI MTS. MUHAMMADIYAH SANINGBAKAR SOLOK
}

\author{
Muhammad Adri ${ }^{1}$ \\ Titi Sriwahyuni \\ Ika Parma Dewi ${ }^{3}$
}

\begin{abstract}
Blended learning is one of model for integration of pedagogic and information and communication technology (ICT) skill of teacher. The community service program aims are to develop an integrated learning environment using Learning Management Sytem and incraasing teacher skill on utilize of ICT as a supporting tool to quality improvement of teaching and learning process at MTs. Muhammadiyah Saningbakar. The ICT skill as well as define on National Curriculum Nasional 2013 become an integrated skill for every teacher. In this programme, two focus activity are defined, first activity is redesign ICT training for teaching and second is development an online learning environment based-on learning management system (LMS) as delivery medium on blended learning. Redesign ICT training including some of main competencies are 1) Course material development, 2) Word Processing, 3) Presentation design, 4) content development, 5) online learning and 6) applied strategic of blended learning. Those skill is needed to fullfill of successfullness requirement of blended learning. Development an online learning management system is using most popular open source course LMS named by Moodle. To achieve development goal some activity is applied as folows : 1) Define an domain name system for MTs. Muhammadiyah Saningbakar, 2) Get a hosting services as online storage for online environment, 3) LMS installation and Configiration, 4) User management, 5) Course and teacher settings and 6) Content uploading and delivery using LMS. Blended learning environment is developed based on MTs. M curriculum, and defined on course setting of LMS into 3 catagories : Islamic, Adaptive, and Subtantive. And each category containing some course which are available on LMS and accessed by student using networking.
\end{abstract}

Keyword: Blended Learning, ICT Skill, Integrated Learning Environment, LMS, Online Learning.

\footnotetext{
${ }^{123}$ Dosen Universitas Negeri Padang
} 


\section{INTISARI}

Blended learning merupakan salah satu model integrasi keterampilan pedagogik dan teknologi informasi dan komunikasi (TIK) guru. Program layanan masyarakat bertujuan untuk mengembangkan lingkungan belajar terpadu dengan menggunakan Learning Management Sytem dan meningkatkan kemampuan guru dalam memanfaatkan TIK sebagai alat pendukung peningkatan kualitas proses belajar mengajar di MTs. Muhammadiyah Saningbakar. Keterampilan TIK serta mendefinisikan Kurikulum Nasional 2013 menjadi keterampilan terpadu bagi setiap guru. Dalam program ini, dua kegiatan fokus didefinisikan, aktivitas pertama adalah mendesain ulang pelatihan TIK untuk pengajaran dan kedua adalah pengembangan lingkungan belajar online berbasis sistem pembelajaran (LMS) sebagai media penyampaian pembelajaran campuran. Mendesain ulang pelatihan TIK termasuk beberapa kompetensi utama adalah 1) Pengembangan materi pelajaran, 2) Pengolah Kata, 3) Desain presentasi, 4) pengembangan konten, 5) pembelajaran online dan 6) menerapkan strategi pembelajaran campuran. Keterampilan tersebut diperlukan untuk memenuhi persyaratan keberhasilan pembelajaran campuran. Pengembangan sistem manajemen pembelajaran online menggunakan LMS open source yang paling populer bernama Moodle. Untuk mencapai tujuan pembangunan beberapa kegiatan diterapkan sebagai berikut: 1) Tentukan sistem nama domain untuk MTs. Muhammadiyah Saningbakar, 2) Mendapatkan layanan hosting sebagai penyimpanan online untuk lingkungan online, 3) pemasangan dan penginstalan LMS, 4) pengelolaan pengguna, 5) Pengaturan kursus dan guru dan 6) Mengunggah dan mengirimkan konten menggunakan LMS. Lingkungan belajar campuran dikembangkan berdasarkan MTs. M kurikulum, dan didefinisikan pada setting kursus LMS menjadi 3 kategori: Islam, Adaptif, dan Subtantive. Dan setiap kategori berisi beberapa kursus yang tersedia di LMS dan diakses oleh siswa yang menggunakan jejaring.

Kata Kunci : Pembelajaran Campuran, Keterampilan TIK, Lingkungan Belajar Terpadu, LMS, Pembelajaran Online 


\section{PENDAHULUAN}

Kehadiran teknologi informasi dan komunikasi (TIK) dalam kehidupan sehari - hari telah mampu mewanai berbagai bidang kehidupan, tidak terkecuali bidang pendidikan. Pemanfaatan TIK dalam pendidikan hampir mewarnai semua sektor kependidikan baik pada sektor manajemen, proses pendidikan, teknologi bahkan evaluasi pendidikan, yang tandai dengan dikeluarkannya berbagai kebijkan yang terkait dengan pemanfaatan TIK oleh pengambil kebijakan pendidikan nasional.

Oetomo dan Priyogoutomo (2004) dalam Muhammad Adri (2011), menegaskan bahwa bidang pendidikan merupakan bidang yang mendapatkan dampak yang cukup berarti dengan kehadiran TIK ini.

$$
\text { Keterampilan }
$$

Teknologi

Informasi dan Komunikasi (TIK) pada Kurikulum Nasional 2013 sudah menjadi keterampilan dasar yang harus dikuasai guru, karena keterampilan TIK sudah "embedded" di dalam semua mata pelajaran, sehingga tidak lagi menjadi satu mata pelajaran yang diajarkan kepada siswa, yang menjadikan keterampilan TIK sebagai keterampilan yang terinternalisasi pada seorang guru, yang akan menjadi fasilitator bagi anak didik yang diajarnya dalam memanfaatkan TIK yang sesuai dengan kebutuhan dalam mata pelajaran yang dibinanya. Keterampilan TIK tidak lagi hanya menjadi milik siswa atau guru dalam bidang TIK, namun sudah menjadi keterampilan umum yang harus dikuasai dengan baik oleh pendidik maupun peserta didik. Hal ini dikarenakan oleh adanya pergeseran paradigma pendidikan sebagai dampak dari kehadiran teknologi ini, sebagaimana diungkapkan oleh Paquette (2004), yang disebut dengan learner-centered model, yang menuntut peran aktif peserta didik dalam mendapatkan instructionalmaterial yang difasilitasi oleh pendidik.

Bagi tenaga pendidik, keterampilan TIK dapat dijadikan sebagai alat untuk meningkatkan produktifitas, efisiensi dan efektifitas dalam bekerja. Dengan menguasai keterampilan TIK secara baik, seorang guru akan dapat mengembangkan berbagai perangkat dan model pembelajaran sehingga dapat meningkatkan perhatian dan minat siswa dalam proses pembelajaran yang dapat disesuaikan dengan kebutuhan tempat dia mengajar. Misalnya penggunaan aplikasi pengolah kata (word processing) untuk menulis dan mengembangkan modul pembelajaran, aplikasi presentasi dengan Microsoft PowerPoint dapat digunakan untuk mengembangkan media pembelajaran dengan dukungan multimedia, interaktif dan imajinatif yang dapat meningkatkan perhatian siswa, perangkat lunak pengolah angka (spreadsheet) dapat digunakan untuk melakukan penghitungan dan pengolahan nilai siswa. Dengan menguasai beberapa aplikasi tersebut di atas, dapat dijadikan sebagai contoh produktifitas yang dapat dihasilkan guru dengan menguasai keterampilan dan pemanfaatan aplikasi TIK.

Sedangkan bagi peserta didik, keterampilan TIK dapat digunakan bagi pengembangan kompetensi diri, ilmu pengetahuan dan keterampilan serta keahilian berkomunikasi. Dengan keterampilan TIK, seorang peserta didik dapat menjadikan teknologi internet sebagau sumber belajar yang kaya dengan berbagai sumber pengetahuan dan keterampilan, bahkan tidak jarang kemudian lembaga pendidikan berhasil menciptakan tenaga ahli dalam bidang TIK. Hal ini sejalan 
dengan apa yang diungkapkan oleh Lukito (2010), yang menyatakan lembaga pendidikan sebagai pemanfaat TIK dan sekaligus penghasil tenaga ahli TIK.

Guru sebagai salah satu komponen terpenting dalam dunia pendidikan merupakan ujung tombak keberhasilan penyelenggaraan pendidikan. Dalam konteks ini, guru mempunyai peran yang sangat besar dan strategis, karena gurulan yang berada di barisan paling depan dalam pelaksanaan pendidikan. Guru langsung berhadapan dengan siswa dan berbagai problematikanya dalam kegiatan pembelajaran, yang di dalamnya mencakup kegiatan pengembangan ilmu pengetahuan dan teknologi serta penanaman nilai-nilai positif melalui bimbingan dan tauladan. Untuk itu sudah selayaknya guru memiliki berbagai kompetensi yang berkaitan dengan tugasnya untuk menjadi guru yang profesional.

$$
\text { Pengembangan keahlian }
$$

berkelanjutan bagi seorang tenaga pendidik adalah suatu keharusan, agar guru dapat menyesuaikan diri seiring dengan perubahan yang terjadi didalam dunia pendidikan. Salah satu perubahan yang terjadi adalah perkembangan teknologi informasi yang sangat cepat, sehingga perlu bagi seorang guru melakukan adaptasi agar dapat mempermudah pelaksanaan tugas yang diembannya. Disamping itu pada aspek kebijakan pendidikan juga terjadi perubahan, khususnya dalam kebijakan keterampilan TIK pada lembaga pendidikan. Sesuai dengan perubahan pada Kurikulum Nasional 2013, pengetahuan dan keterampilan TIK sudah menjadi keterampilan yang "embedded" di dalam semua mata pelajaran, sehingga tidak lagi menjadi satu mata pelajaran utuh yang diajarkan kepada siswa, yang menjadikan keterampilan TIK sebagai keterampilan yang ter-internalisasi pada seorang guru profesional, dan diharapkan guru akan menjadi fasilitator bagi anak didik yang diajarnya dalam memanfaatkan TIK yang sesuai dengan kebutuhan dalam mata pelajaran yang dibinanya.

Madrasah Tsanawiyah (MTs) Muhammadiyah Saningbakar merupakan salah satu MTs yang berada di bawah binaan Majlis Pendidikan Menengah Pimpinan Cabang Muhammadiyah Kab. Solok, yang saat ini telah terakreditasi $B$ yang tertuang dalam Sertifikat Akreditasi No. 1044/BAPSM/LL/X/2016, dengan nilai 83, yang menegaskan sebagai salah satu Madrasah yang memiliki reputasi yang baik. Banyak prestasi yang telah diraih oleh pelajar MTs.M ini, diantaranya 5 besar terbaik hasil UN MTs tahun 2016 dan lulusan dengan nilai UN tertinggi MTs Swasta se Kab. Solok, tahun 2015 (MTs.M, 2017a).

Madrasah ini dibina oleh 28 orang tenaga pendidik, terdiri dari 4 orang guru PNS yang diperbantukan oleh Departemen Agama, 6 orang guru PNS dalam upaya Penambahan Jam Pembelajaran dan 18 orang guru honorer yang pembiayaannya didanai dari SPP Siswa dan swadaya masyarakat kenagarian Saniangbaka, dan alumni (MTs.M, 2017a).

Saat ini MTs. M Saningbakar memiliki 176 orang siswa yang terdiri dari 8 kelas, yaitu, Kelas 7 terdiri dari 3 kelas, Kelas 8 sebanyak 3 kelas dan Kelas 9 memiliki 2 kelas. Untuk menunjang penyelenggaraan pendidikan, MTs.M Saningbakar memiliki 2 gedung permanen, yang dibanguns secara swadaya oleh masyarakat nagari, yang layak menampung 6 kelas pembelajaran, mushalla, ruang pustaka, laboratorium komputer dan laboratorium IPA. Khusus Laboratorium Komputer telah digunakan untuk penyelenggaraan 
Ujian Nasional Berbasis Komputer (UNBK) SMA Negeri $2 \mathrm{Kec}$. X Koto Singkarak, yang menunjukkan bahwa kompetensi Komputer tenaga teknisi dan guru sudah baik sebagai lokasi penyelenggara UNBK.

Pada saat survey awal dilakukan, pada tanggal $26-27$ April 2017, diperoleh informasi bahwa upaya penyempurnaan terus dilakukan, dan saat ini MTs.M Saningbakar telah memiliki perangkat multimedia yang dapat digunakan sebagai alat bantu dalam proses pembelajaran, yang terdiri dari seperangkat multimedia dan audiovideo, 4 buah LCD Proyektor dan seperangkat sound system terintegrasi yang terpasang di semua ruang kelas, dan akses internet 3 Mbps, melalui koneksi Telkom
Speedy, sebagai wujud keseriusan pimpinan madrasah dan donatur dalam menyambut kebijakan pemerintah dalam Kurikulum Nasional 2013, dengan ditiadakannya mata pelajaran TIK.

Setelah melakukan diskusi dengan pimpinan Madrasah, kemudian tim menyebarkan angket awal kepada majelis guru, yang digunakan untuk melihat sejauhmana kesiapan guru MTs. M Saningbakar dalam mengimplementasikan TIK sebagai bagian terintegrasi dari Kurikulum 2013, dengan merujuk kepada kompetensi TIK yang dikembangkan oleh Intel Education (2007), dan Education Toolkit yang dikembangkan oleh Lim, at.al (2010), maka diperoleh data sebagai berikut:

Tabel 1. Data survey awal Kompetensi TIK Guru MTs. M Saningbakar

\begin{tabular}{|l|l|l|l|l|l|}
\hline No. & Kompetensi TIK Dasar & Pemula & Menengah & Mahir & Jumlah \\
\hline 1 & Pengoperasian Komputer & 18 & 6 & 4 & 28 \\
\hline 2 & Aplikasi Pengolah Kata & 12 & 10 & 6 & 28 \\
\hline 3 & Aplikasi Presentasi & 16 & 8 & 4 & 28 \\
\hline 4 & Aplikasi Pengolah Angka & 10 & 16 & 2 & 28 \\
\hline 5 & Akses Internet & 6 & 14 & 8 & 28 \\
\hline 6 & Internet Resources & 15 & 9 & 4 & 28 \\
\hline 7 & Online Learning TTK & 20 & 6 & 2 & 28 \\
\hline 8 & $\begin{array}{l}\text { Integrasi Internet dan } \\
\text { dalam Pembelajaran }\end{array}$ & 4 & 2 & 28 \\
\hline
\end{tabular}

Sumber : MTs.M, 2017b

Dari Tabel 1 dapat dilihat bahwa rata-rata kompetensi TIK Dasar yang diharapkan dimiliko oleh Guru untuk dapat mengimplementasikan dukungan TIK dalam Mata Pelajaran masih berada pada level pemula, yang pada umumnya data ini diperoleh pada kelompok guru honorer, yang berdasarkan diskusi dengan pimpinan Madrasah diperoleh informasi bahwa kelompok guru honorer ini adalah kelompok guru yang cendrung berganti, yang disebabkan oleh adanya diantara mereka yang lulus sebagai Guru PNS, pindah tugas dan membina rumah tangga. Sedangkan pada level menengah umumnya didapatkan dari kelompok guru PNS baik yang diperbantukan oleh Depag maupun guru PNS penambahan jam, dan sisanya dari guru honorer senior yang telah mengikuti beberapa jenis diklat TIK sebelumnya. Sedangkan yang mahir diperoleh dari guru bidang TIK dan bidang Sains eksakta.

Satu data yang cukup menggembirakan adalah pada pengaksesan internet, yang hanya sebagian kecil guru yang termasuk dalam ketegori pemula, sebagian besar lainnya berada pada level menengah dan mahir. Artinya bahwa 
akses internet tidak lagi menjadi kendala bagi guru di Madrasah ini, karena mayoritas mereka telah melakukan akses internet dengan baik. Namun dari diskusi lanjutan yang dilakukan, diperoleh informasi bahwa mayoritas guru mengakses internet menggunakan gadget dan smartphone untuk kebutuhan jejaring sosial dan media, sehingga belum termanfaatkan untuk kebutuhan pembelajaran dengan baik.

Dari uraian data tersebut di atas dapat dilihat bahwa ada kencendrungan pemanfaatan TIK dan Internet oleh Guru, namun pemanfaatannya belum terarah dengan baik untuk kepentingan pendidikan dan pengajaran. Oleh sebab itu, perlu upaya yang cermat dan terarah untuk meningkatkan keterampilan TIK ini bagi guru, yang diharapkan akan bermuara pada peningkatan kompetensi dan pemanfaatan TIK oleh siswa.

Hal ini dapat diwujudkan dengan mengaplikasikan pemanfaatan TIK dalam pembelajaran melalui proses integrasi antara Pemanfaatan TIK dengan Pembelajaran di kelas, yang disebut dengan Blended Learning.

Blended learning saat ini dianggap sebagai salah satu jawaban atas persoalan ketidak seimbangan kemajuan teknologi dengan daya serap pemanfaat teknologi tersebut di dalam dunia pendidikan. Sehingga secara proaktif dan bersama-sama pendidik dan peserta didik memanfaatkan teknologi sebagai pendukung proses pembelajaran (Adri, 2011).

Oleh sebab itu dirasa perlu dan mendesak untuk segera memberikan pengetahuan dan berbagi keterampilan dalam pemanfaatan TIK dalam proses pembelajaran ini antara perguruan tinggi dengan lembaga pendidika di bawahnya. Dimana perguruan tinggi dipandang lebih berpengalaman dalam memanfaatkan TIK dalam proses pendidikan dan dianggap berhasil dalam mewujudkan integrasi teknologi dengan proses pembelajaran di kelas. Maka pada kegiatan Penerapan Ipteks ini diusulkan kegiatan Peningkatan Keterampilan TIK Guru melalui Pelatihan Blended Learning di MTs. Muhammadiyah Saningbakar Kec.X Koto Singkarak Kabupaten Solok, sehingga diharapkan akan mampu meningkatkan kualitas pendidikan dan pengajaran di Madrasah yang dibangun dengan dan diselenggrakan melalui swadaya masyarakat sepenuhnya, akan akan bermuara terangkatnya derajat pendidikan di Madrasah ini.

\section{PENDEKATAN PEMECAHAN} MASALAH

Metode pemecahan masalah yang digunakan untuk memecahkan permasalahan yang dihadapi oleh mitra adalah melalui pendidikan dan latihan kepada khalayak sasaran tentang TIK dan strategi pembelajaran dengan model Blended learning, yang dapat digambarkan dengan ilustrasi berikut :

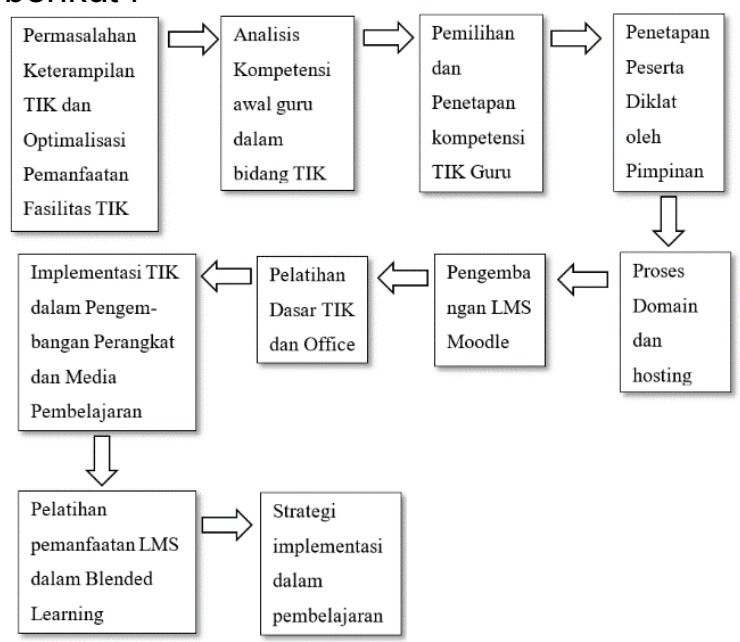

Gambar 1. Metode Pemecahan Masalah

Gambar 1 memperlihatkan kerangka pemecahan masalah mitra 
dalam Penerapan Ipteks ini, yang diawali dengan tiga langkah utama yang telah dilakukan pada saat survey awal kegiatan. Studi awal ini dilakukan terhadap permasalahan yang dihadapi oleh mitra, yang kemudian dilanjutkan dengan studi terhadap kompetensi awal guru dalam TIK, sebagaimana telah diperlihatkan pada Tabel 1, dan penetapan kompetensi TIK yang akan diberikan dalam Penerapan Ipteks ini. Selanjutnya akan ditetapkan oleh Pimpinan Madrasah calon peserta Diklat TIK, berdasarkan pengelompokan kompetensi awal yang dimiliki, sehingga dengan pengelompokan ini diharapkan pelaksanaan program akan lebih tepat sasaran dan efisien. Sembari melakukan sosialisasi kepada majelis guru, tentang persiapan penyelenggaraan program Penerapan Ipteks, maka dilakukan tahapan pendaftaran domain Madrasah dan pengembangan LMS Moodle oleh tim pelaksana, sehingga siap untuk digunakan pada saat pelaksanaan kegiatan pelatihan dalam Penerapan Ipteks ini, yang mencakup pengembangan LMS Moodle, pengembangan Modul Penggunaan bagi user dan Modul Pengelolaan Pembelajaran.

Tahapan selanjutnya adalah menyelenggarakan kegiatan pendidikan dan pelatihan bagi Guru dalam pemanfaatan TIK sebagai perangkat pendukung dalam pengembangan perangkat pembelajaran dan penyelenggaraan proses pendidikan dan pembelajaran dengan dukungan TIK dan internet, melalui aplikasi Pengolah Kata, Presentasi dan LMS. Kegiatan ini akan diikuti oleh 30 orang peserta yang terdiri seluruh guru bidang studi di MTs. Muhammadiyah Saningbakar, sebanyak 28 orang dan 2 orang guru undangan yang berasal dari MTs. Muhammadiyah Sumani dan MTs.
Muhammadiyah Kacang, sebagai sekolah mitra dibawah binaan Majelis Pendidikan Dasar dan Menengah Pimpinan Ranting Muhammadiyah Kec. X Koto Singkarak, Kab. Solok.

\section{HASIL DAN PEMBAHASAN}

1. Pembekalan Kompetensi TIK Guru

Pembekalan kompetensi TIK guru menjadi salah satu faktor keberhasilan penyelenggaraan Model Blended Learning.

Penetapan dan pemilihan kompetensi TIK guru mengacu kepada kesepakatan yang telah ditetapkan pada saat kegiatan konsolidasi dilaksanakan yaitu :
a. Memahami dan menguasai pengoperasi dasar perangkat komputer dalam lingkungan Sistem Operasi Windows
b. Menguasai dasar-dasar penggunaan aplikasi Office.
c. Menguasari dasar-dasar pengaksesan Internet dan pencarian informasi.

\section{Pengembangan LMS \\ Pengembangan LMS yang} akan digunakan dalam proses pembelajaran dengan model blended learning, merupakan salah satu kegiatan utama dalam kegiatan ini. Proses pengembangan ini saat ini masih dalam proses pelaksanaan, karena membutuhkan kustomisasi yang disesuaikan dengan kebutuhan MTs. M Saniangbakar, dan akan dipublikasikan pada saat proses online hosting selesai dilaksanakan

\section{Hasil Pengembangan LMS Blended Learning \\ Dalam proses pengembangan} LMS yang akan digunakan dalam Blended Learning di MTs. Muhammadiyah Saningbakar, dilakukan dalam beberapa tahapan: 
a. Proses Registrasi Domain dan Hosting

Proses registrasi domain dan hosting dilakukan sesuai dengan prosedur yang ditetapkan oleh Pengelola Domain Indonesia (PANDI), yang meliputi :

1) Identitas Pengusul (KTP)

2) Surat Permohonan Nama Domain

3) Surat Kuasa Pengurusan Domain

Proses registrasi ini dilakukan, dengan pengusulan nama domain yang adalah

http://mtsmsaningbakar.sch.id, dengan menggunakan domain resmi School of Indonesia (sch.id).

b. Pengembangan dan Instalasi LMS Moodle

Pengembangan LMS Open Source ini menggunakan aplikasi LMS Moodle dengan online installer yang tersedia pada layanan hosting online oleh penyedia jasa hosting. Proses pengembangan ini dikembangkan dengan pendekatan kustomisasi, kerjasama dengan antara Tim Pelaksana dengan Tim yang ditunjuk oleh Pimpinan Madrasah

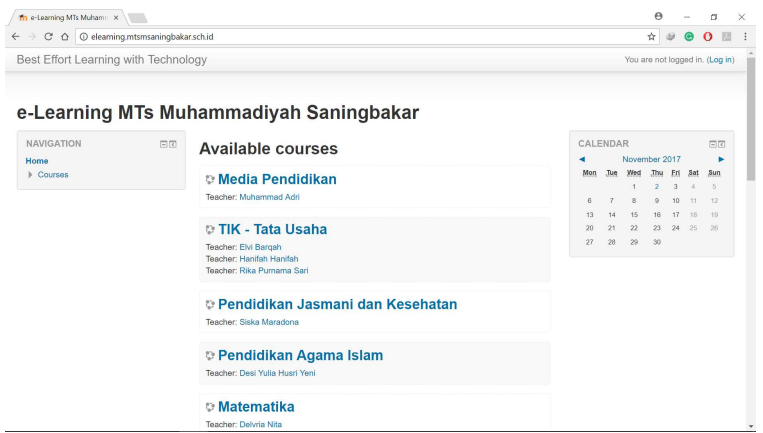

Gambar 2. Hasil LMS Blended Learning

$\begin{array}{lr}\text { 4. } & \begin{array}{l}\text { Pemannfaatan } \\ \text { Implementasi }\end{array} \\ \text { Learning } & \text { Blended } \\ \text { Setelah LMS dikembangkan } \\ \text { dan online pada sub domain elearning }\end{array}$

MTs. M Saningbakar pada alamat sub domain

http://elearning.mtsmsaningbakar.sch.i $\underline{\mathrm{d}}$, dengan agenda :

a. Pembuatan Akun Guru Peserta Penerapan IPTEKS

Pembuatan akun guru ini dilakukan agar para Guru memiliki hak akses ke dalam sistem LMS e-Learning MTs. M Saningbakar, sehingga dapat mengelola kegiatan pembelajaran melalui eLearning.

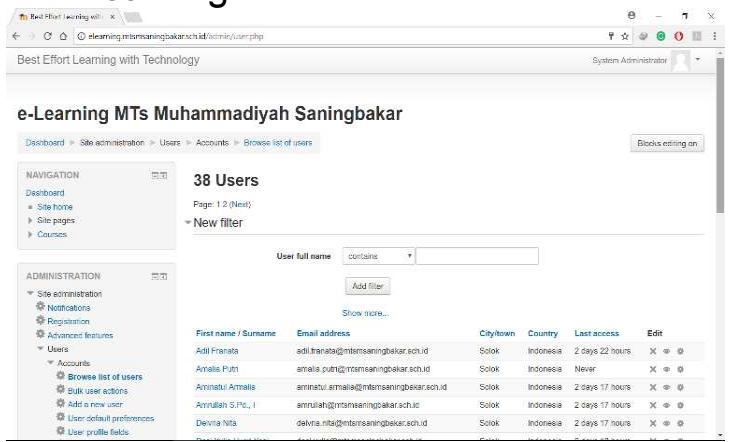

Gambar 3. Pembuatan Akun User Guru pada LMS MTs. M Saningbakar

b. Pembuatan Daftar Mata Pelajaran aktif pada LMS

Mata pelajaran yang dibuat dan diaktivasi pada LMS disesuaikan dengan mata pelajaran yang dibina oleh masing-masing guru.

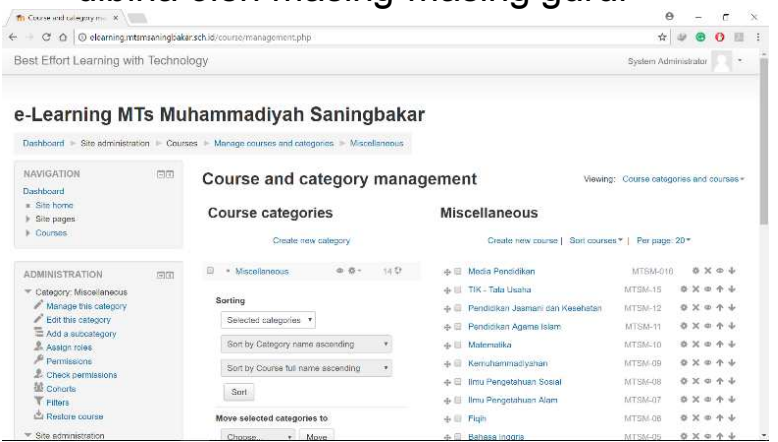

Gambar 4. Pembuatan Daftar Mata Pelajaran yang dibina oleh Guru Peserta Penerapan IPTEKS

c. Upload materi dan modul pembelajaran Implementasi Blended Learning oleh guru diawali dengan aktifitas upload materi dan modul 


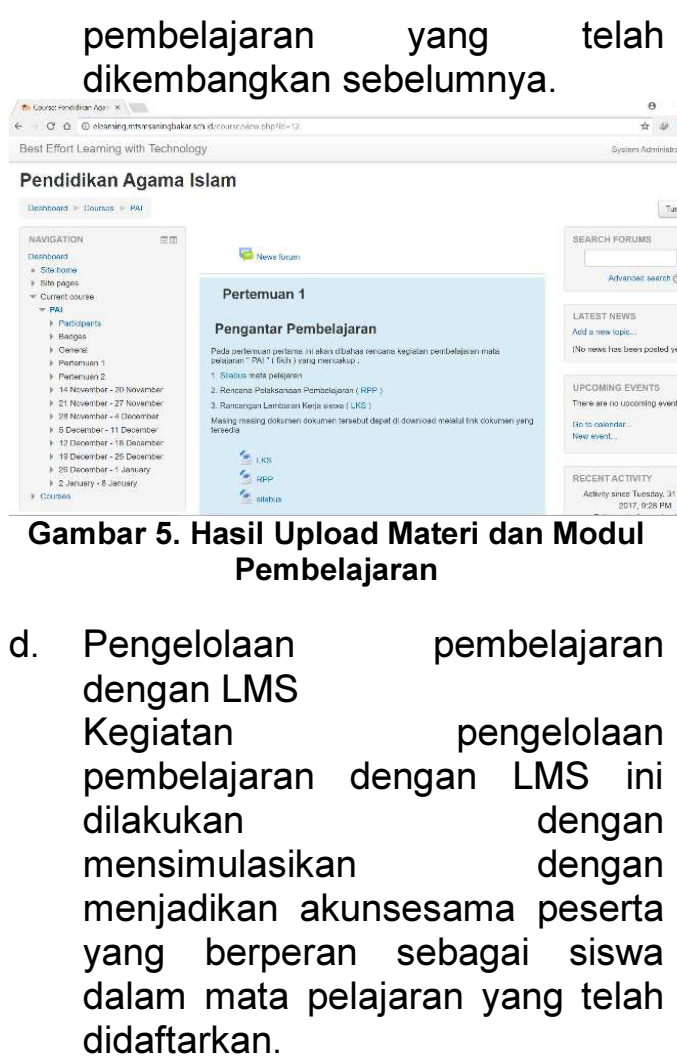

\section{KESIMPULAN}

Berdasarkan hasil pengembangan Blended Learning yang telah dilaksanakan dapat disimpulkan sebagai berikut :

a. Kegiatan Penerapan IPTEKS ini, telah mampu meningkatkan kompetensi dasar teknologi informasi para guru di MTs Muhammadiyah Saningbakar Solok, khususnya yang berkaitan dengan profesi guru, seperti Word Processing, Spreadsheet dan Media Pembelajaran.

b. Pengembangan Online learning dengan Learning Management System (LMS) di MTs. Muhammadiyah Saningbakar, dapat dijadikan sebagai penggerak bagi peningkatan kompetensi dan pemanfaatan TIK dalam pembelajaran di lingkungan Madrasah. c. Implementasi pembelajaran yang mengintegrasikan Online learning dengan pembelajaran di kelas, telah memberikan pengalaman baru bagi Guruguru di MTs. Muhammadiyah Saningbakar dalam memanfaatkan TIK dalam pembelajaran.

Beberapa hal berikut ini dapat disarankan bagi peningkatan kapasitas Madrasah dalam pemanfaatan TIK, antara lain :

a. Kegiatan yang telah dilaksanakan baru dapat dijadikan sebagai "trigger" dalam memberikan nilai-nilai inovasi pembelajaran dengan dukungan TIK, oleh karena itu perlu upaya mandiri dari Guru dan Madrasah untuk meningkatkan kompetensi yang telah didapat

b. Dukungan kebijakan Pimpinan Madrasah dapat dijadikan sebagai pilar bagi keberhasilan implementasi Blended Learning di MTs. Muhammadiyah Saningbakar Solok

c. Perlu upaya kerjasama yang berkelanjutan bagi keberhasilan implementasi TIK dalam Pembelajaran, sehingga dapat meningkatkan kualitas proses pembelajaran dan pendidikan di Madrasah.

\section{DAFTAR PUSTAKA}

[1] Dracoola. 2017. Pedoman dan Prosedur Pendaftaran Domain Indonesia, Surabaya: PT. Dracoola Multimedia, diakses pada alamat http://dracoola.com, pada 4 April 2017.

[2] Intel Education. 2007. Master Teacher Training, Implementasi Keterampilan TIK bagi Guru, Jakarta: Intel Education Indonesia. 
[3] Lim, Cher Ping, et.al. 2010. Leading ICT in Education Practice, A Capacity-Building toolkit for Teacher Education Institution in The Asia-Pacific, Australia : School of Education, Edith Cowan University.

[4] Lukito Edi Nugroho. 2010. Pemanfaatan Teknologi Informasi pada Perguruan Tinggi, Yogyakarta : Gava Media.

[5] MTs M. 2017. Statistik Data Guru dan Siswa MTs. Muhammadiyah Saningbakar, Saningbakar Solok: Tata Usaha MTs. M Saningbakar.

[6] Muhammad Adri. 2011. Pengembangan Model Blended Learning pada Mata Kuliah Komunikasi Data dan Jaringan Komputer, makalah pada Seminar Internasional Teknologi Informasi dan Pendidikan, Padang, 29 Januari 2011.

[7] Paquette, Gilbert. 2004. Instructional Engineering in Networked Environmnet, San Francisco, USA : Pfeiffer, john Wiley \& Sons

[8] Rice, William. 2015. Moodle ELearning Course Development, 3rd Edition: A complete guide to create and develop engaging elearning courses with Moodle, Birmingham, UK : Packt Publishing.

[9] van Dijk, Jan A. G. M. and van Deuresen, Alexander. 2014. Digital Skill, unlocking the Information Society, New York, USA : Palgrave MacMillan. 